\title{
Article
}

\section{Quality of Life Outcomes According to Differential Nusinersen Exposure in Pediatric Spinal Muscular Atrophy}

\author{
Meaghann S. Weaver ${ }^{1,2}$, Alice Yuroff ${ }^{3}$, Sarah Sund ${ }^{3}$, Scott Hetzel ${ }^{3}$ and Matthew A. Halanski ${ }^{1, *}$ \\ 1 Children's Hospital and Medical Center, Omaha, NE 68114, USA; meweaver@childrensomaha.org \\ 2 National Center for Ethics in Healthcare, Washington, DC 20420, USA \\ 3 School of Medicine and Public Health, University of Wisconsin-Madison, Madison, WI 53706, USA; \\ Alice.Yuroff@fammed.wisc.edu (A.Y.); Sund@ortho.wisc.edu (S.S.); hetzel@biostat.wisc.edu (S.H.) \\ * Correspondence: mhalanski@childrensomaha.org; Tel.: +402-955-4160; Fax: +402-955-6330
}

Citation: Weaver, M.S.; Yuroff, A.; Sund, S.; Hetzel, S.; Halanski, M.A. Quality of Life Outcomes According to Differential Nusinersen Exposure in Pediatric Spinal Muscular Atrophy. Children 2021, 8, 604. https:// doi.org/10.3390/children8070604

Academic Editor:

Rudolf Korinthenberg

Received: 15 June 2021

Accepted: 13 July 2021

Published: 17 July 2021

Publisher's Note: MDPI stays neutral with regard to jurisdictional claims in published maps and institutional affiliations.

Copyright: (c) 2021 by the authors. Licensee MDPI, Basel, Switzerland. This article is an open access article distributed under the terms and conditions of the Creative Commons Attribution (CC BY) license (https:/ / creativecommons.org/licenses/by/ $4.0 /)$.

\begin{abstract}
The purpose of this study was to explore early changes in patient and family caregiver report of quality of life and family impact during the transitional period of nusinersen use. Communication; family relationships; physical, emotional, social, and cognitive functioning; and daily activities were measured using Pediatric Quality of Life modules (Family Impact Modules and both Patient and Proxy Neuromuscular-Specific Reports) pre- and post-nusinersen exposure. A total of 35 patients with SMA (15 Type 1, 14 Type 2, and 6 Type 3) were grouped according to nusinersen exposure. When analyzed as a whole cross-sectional clinical population, no significant differences were found between the initial and final surveys. Nusinersen therapy was associated with improved communication and emotional functioning in subsets of the population, particularly for patients on maintenance therapy for longer duration. Several unexpected potentially negative findings including increases in family resources and trends towards increases in worry warrant further consideration. Further research is warranted to explore the impact of novel pharmaceuticals on quality of life for children with SMA longitudinally to optimize clinical and psychosocial outcomes.
\end{abstract}

Keywords: spinal muscular atrophy; quality of life; child neurology; patient-reported outcomes; neuromuscular

\section{Introduction}

Spinal muscular atrophy (SMA) is an autosomal-recessive, progressive neuromuscular disease associated with extensive morbidity related to muscular atrophy and proximal muscle weakness with risk for early mortality. In the past, children with SMA Type I seldom survived beyond the first few years of life even with mechanical respiratory support [1]. With the recent introduction of novel pharmaceutical interventions such as nusinersen $[1,2]$ and gene therapies [3], children with SMA now have potentially increased lifespans and improved quality of life (QOL). A modified 2'-O-methoxyethyl antisense oligonucleotide by the name of nusinersen was approved by the Food and Drug Agency in December of 2016 with subsequent evidence of high efficacy and safety [4,5]. Quality of life outcomes associated with nusinersen use have been less studied.

A paucity of data exists on how children with SMA depict quality of life from their own report or how family caregivers of children with SMA perceive the diagnosis impacts the child and family before, during, and after the early phases of introducing nusinersen. As survival may be prolonged through medical advancements, learning about the child's QOL remains a compassionate, competent clinical care priority [6,7]. This knowledge can help clinicians partner with the child and family for symptom or support interventions intended to further support lived experiences. QOL is defined as "an individual's perception of his/her position in life in the context of culture and value systems in which he/she lives and in relation to wellness, goals, expectations, standards, and concerns" [8]. By investing in the subjective perspective of pediatric patients and their family caregivers before and after introduction of a therapy such as nusinersen, clinical teams are then positioned to 
better appreciate how therapies may trend with enhanced or burdened overall perceptions of health or wellness.

In 2016, prior to the widespread use of nusinersen at our institution, we began a study to evaluate the sensitivity of the Caregiver Priorities and Child Health Index of Life with Disabilities $\left(\mathrm{CPCHILD}^{\mathrm{TM}}\right)$ questionnaire and PedsQL ${ }^{\mathrm{TM}} 3.0$ Neuromuscular Module NMM (PedsQL) outcome measures to detect uniqueness between the between patient and proxy measurements and between SMA types [9]. We extended collection of the PedsQL outcome measures through 2019 to detect early changes in PEdsQL measurements in our clinical population during the transitional period of nusinersen use. This study highlights the early differences in PedsQL according to nusinersen exposure.

\section{Materials and Methods}

\subsection{Participants and Setting}

The University of Wisconsin-Madison Minimal Risk Institutional Review Board approved the study methodology and the ethics of implementation of this health sciences study in October 2015. Children and their family caregiver proxy were enrolled from November 2016 to September 2019. Eligibility criteria included patients with a diagnosis of SMA currently younger than age 18 receiving care at the outpatient neuromuscular clinic.

A letter was sent to eligible children/families providing details about the voluntary research study opportunity. The letter was mailed one to two weeks prior to the eligible subject's scheduled outpatient visit. The study coordinator then offered to meet with the patient and family caregiver through an informed consent process at the clinic visit. iPads linked wirelessly to the RedCAP@ study database served as the survey response collection modality. The initial study included cross-over assessment of both the PedsQL ${ }^{\mathrm{TM}}$ 3.0 Neuromuscular Module (NMM) (for child-report and proxy-report) coupled with the PedsQL ${ }^{\mathrm{TM}}$ Family Impact Module (FIM) or CPCHILD ${ }^{\mathrm{TM}}$ questionnaire [9]. We continued collection of outcome measures until 2019 using the PedsQL measures as these appeared the most sensitive in our previous study in this population [9].

The electronic medical record was reviewed in a retrospective nature to determine the nusinersen status at the time of each initial questionnaire to produce four cohorts: (1) No Intent of Treatment, which included patients who did not start nor proceeded with any nusinesen treatment at time of final outcome measure; (2) Intent of Treatment, which included patients not on any treatment at time of initial questionnaire but began therapy after the initial assessment; (3) Loading Phase, which included patients within the first two months of treatment (received four intrathecal infusions) at the first quality of life (QOL) assessment; and (4) Maintenance Phase, which included patients on maintenance schedule (infusion every 4 months) at the time of initial QOL assessment. Cohorts 2-4 were receiving maintenance dosing at the time of their final survey (Figure 1). Pairwise differences between initial and final scores were analyzed within each cohort.

\subsection{Methods}

The PedsQL 3.0 Neuromuscular Module (NMM) includes 25 items covering core dimensions: (1) About My Neuromuscular Disease (17 items with emphasis on physical functioning), (2) Communication (3 items), and (3) About Our Family Resources (5 items). Child self-report and family proxy-reports are summarized for the past month. The PedsQL ${ }^{\mathrm{TM}} \mathrm{NMM}$ maintains Cronbach's coefficient alpha scores $>0.77$ for each scale dimension in SMA cohorts [10-12]. 


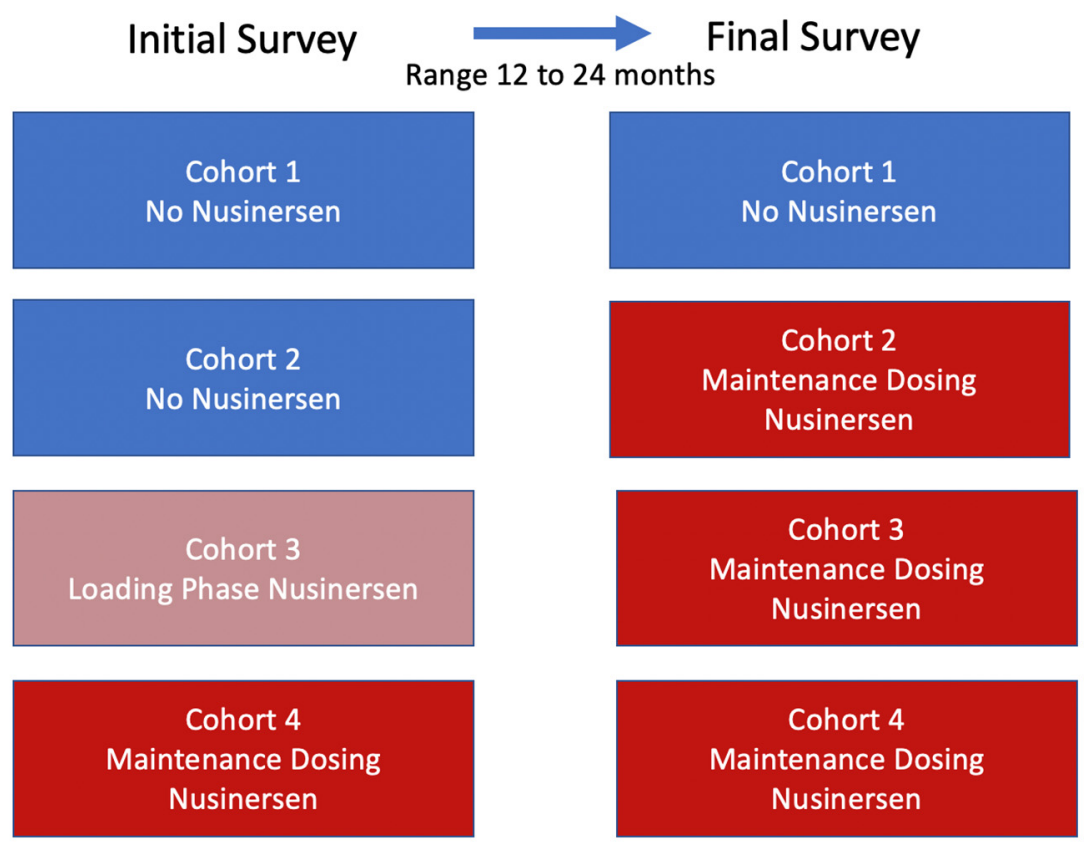

Figure 1. Nusinersen exposure at initial and final study timepoints. Legend-Transitions between nusinersen exposure during study initiation and follow-up timepoint including Cohort 1 which remained nusinersen naïve throughout; Cohort 2 which transitioned from no nusinersen to maintenance dosing; Cohort 3 which transitioned from loading phase to maintenance dosing; and Cohort 4 which remained on maintenance dosing with longest steady exposure to nusinersen.

The 36 item PedsQL Family Impact Module (FIM) measures parental perceptions of parental self-reported physical functioning (6 items), emotional functioning (5 items), social functioning (4 items), cognitive functioning ( 5 items), communication ( 3 items), and worry (5 items). The parent is reporting on his/her own well-being rather than the child's well-being over the past month. The PedsQL FIM explores the impact of the child's SMA diagnosis and neuromuscular health on family daily activities ( 3 items) and family relationships ( 5 items). In validation studies, Cronbach's coefficient alpha scores were $>0.82$ for PedsQL FIM scales [13].

\subsection{Statistical Analysis}

Survey total scores and sub-scores were calculated. Results were summarized using mean (SD) at each timepoint and the difference of means between the initial and final survey reported. Separate analyses were then performed based on SMA type or initial nusinersen status for those receiving nusinersen. Subjects in Cohorts 2 and 3 (no nusinersen at baseline and those in the loading phase) were also pooled together to assess any changes occurring once maintenance dosing is achieved. This combined cohort was then compared with those at on maintenance dosing at the time of initial survey. Comparisons of survey scores across two-level factors utilized t-tests, while comparisons of survey scores across three-level factors utilized ANOVA models. Due to the magnitude of testing, $p$-values were Benjamini-Hochberg corrected to control for false discovery rate [14]. Significant ANOVA $p$-values resulted in post hoc pairwise t-tests with Holm-adjusted $p$-values [15]. All tests had an adjusted alpha level of 0.05 and were conducted using $R$ for Statistical Computing Version 3.5 [16].

\section{Results}

\subsection{Participants}

A total of 35 patients with SMA: 15 Type 1, 14 Type 2, and 6 Type 3, with a respective average age at initial survey $(2.7+/-2.1),(11.2+/-5.9),(10.2+/-2.7)$ years and an average $1.8(+/-0.5)$ years between surveys were analyzed. Five patients were in Cohort 1 , the 
non-treatment control cohort containing two patients with Type 1, one patient with Type 2, and two patients with Type 3 . Cohort 2 had $n=8$ that had not started nusinersen at the time of the first survey, Cohort 3 had $n=11$ that were in the loading phase of nusinsersen at the time of the first survey, and Cohort 4 had $n=11$ subjects already at the maintenance phase of treatment at the time of initial PedsQL. All patients in Cohorts 2-4 were on maintenance dosing at the time of the final QOL survey.

\subsection{Collective Cohort}

When analyzed as a whole cross-sectional clinical population (pooling Cohorts 2-4), no significant differences were found between the initial and final surveys for family impact (Table 1), child self-report (Table 2), or proxy family caregiver report (Table 3 ).

Table 1. PedsQL-Family Impact Module.

\begin{tabular}{ccccc}
\hline & \multicolumn{2}{c}{ Full Cohort $(\boldsymbol{n}=\mathbf{3 0})$} \\
\hline Variable & Baseline & Follow Up & Difference & $p$-Value \\
\hline Physical Functioning & $54.9(21.8)$ & $53.6(20.5)$ & $-1.2(14.9)$ & 0.65 \\
Emotional Functioning & $56.5(21.5)$ & $60.2(20.6)$ & $3.7(14.2)$ & 0.168 \\
Social Functioning & $50.4(23.8)$ & $50.6(24.7)$ & $0.2(18.5)$ & 0.951 \\
Cognitive Functioning & $56.2(24.9)$ & $59.6(22.1)$ & $3.3(18.3)$ & 0.326 \\
Communication & $50.3(19.8)$ & $54.2(23.1)$ & $3.9(17.1)$ & 0.222 \\
Worry & $51.3(19.5)$ & $55.7(21.0)$ & $4.3(15.6)$ & 0.138 \\
Daily Activities & $33.3(23.1)$ & $37.2(29.4)$ & $3.9(21.9)$ & 0.338 \\
Family Relationship & $60.0(25.2)$ & $63.7(26.8)$ & $3.7(22.4)$ & 0.377 \\
PedsQL Family Impact Total Score & $52.7(18.9)$ & $55.3(19.5)$ & $2.5(11.0)$ & 0.218 \\
Parent HRQL Summary Score & $54.6(19.8)$ & $56.0(19.5)$ & $1.3(12.7)$ & 0.574 \\
Family Functioning Score & $50.0(22.3)$ & $53.8(26.5)$ & $3.8(19.6)$ & 0.304 \\
\hline
\end{tabular}

${ }^{*}$ Reported mean (SD); $p$-value from paired $t$-tests.

Table 2. Child Self-Repot PedsQL.

\begin{tabular}{ccccc}
\hline & \multicolumn{2}{c}{ Full Cohort $(\boldsymbol{n = 1 6 )})^{*}$} \\
\hline Variable & Baseline & Follow Up & Difference & $p$-Value \\
\hline Neuromuscular Disease & $56.7(17.7)$ & $56.2(17.4)$ & $-0.5(12.0)$ & 0.865 \\
Communication & $60.4(40.4)$ & $66.7(30.5)$ & $7.6(23.4)$ & 0.308 \\
Family Resources & $60.4(25.7)$ & $70.7(18.0)$ & $9.5(18.0)$ & 0.108 \\
Total & $58.2(17.6)$ & $59.9(14.9)$ & $1.7(9.9)$ & 0.497 \\
\hline
\end{tabular}

* Reported as mean (SD); $p$-values are from paired $t$-tests.

Table 3. Proxy -Report (Family Caregiver) PedsQL.

\begin{tabular}{ccccc}
\hline & \multicolumn{2}{c}{ Full Cohort $(\boldsymbol{n}=\mathbf{3 0}){ }^{*}$} \\
\hline Variable & Baseline & Follow Up & Difference & $p$-Value \\
\hline Neuromuscular Disease & $54.9(16.5)$ & $53.8(15.7)$ & $-1.1(12.1)$ & 0.625 \\
Communication & $43.9(38.1)$ & $48.1(37.1)$ & $4.2(17.5)$ & 0.202 \\
Family Resources & $50.8(22.7)$ & $55.3(18.8)$ & $4.5(17.1)$ & 0.16 \\
Total & $52.7(17.4)$ & $53.3(16.2)$ & $0.6(10.6)$ & 0.755 \\
\hline
\end{tabular}

* Reported as mean (SD); $p$-values are from paired t-tests.

After sub-analyzing the data by SMA type and cohort (nusinersen status at the initial survey), several significant differences and trends were identified (Tables 4 and 5). In the Family Impact Module, improvements in emotional functioning were observed for children $(n=8)$ that progressed from no treatment to maintenance therapy $(56.2+/-7.5 \rightarrow 65.4+/-15.3$, $p=0.014)$. 
Table 4. Significant Difference in Quality of Life Scales by Cohort.

\begin{tabular}{ccccccc}
\hline Module & Domain & Cohort & Baseline & Follow Up & Difference & $p$-Value \\
\hline Child-PedsQL & Worry & SMA 1, $n=2$ & $36.7(15.3)$ & $71.2(11.8)$ & $31.7(2.9)$ & 0.003 \\
Child-PedsQL & Total Quality of Life & SMA 3, $n=3$ & $68.4(13.1)$ & $73.0(12.8)$ & $4.6(2.2)$ & 0.068 \\
Parent-PedsQL & Communication & SMA 3, $n=4$ & $52.1(25.8)$ & $64.6(31.5)$ & $12.5(8.3)$ & 0.058 \\
Parent-PedsQL & Family Resources & SMA 3, $n=4$ & $58.8(12.5)$ & $68.8(15.5)$ & $10.0(7.1)$ & 0.066 \\
Family Impact & Worry & SMA 1, $n=13$ & $45.0(12.7)$ & $50.8(12.6)$ & $5.8(9.8)$ & 0.054 \\
Family Impact & Daily Activities & SMA 2, $n=13$ & $39.1(28.1)$ & $52.6(32.5)$ & $13.5(23.9)$ & 0.065 \\
\hline
\end{tabular}

SMA 1, 2, and 3 reflect diagnostic subtype. colors are useful to reveal statistical significance reached vs. close.

Table 5. Significant Difference in Quality of Life Scales by Timeframe.

\begin{tabular}{|c|c|c|c|c|c|c|}
\hline Module & Domain & Cohort & Baseline & Follow Up & Difference & $p$-Value \\
\hline Child-PedsQL & Family Resources & L-M, $n=7$ & $52.5(26.4)$ & $71.7(15.4)$ & $23.0(12.5)$ & 0.015 \\
\hline Parent-PedsQL & Communication & 0 or $\mathrm{L}, n=19$ & $45.2(34.5)$ & $53.9(33.7)$ & $8.8(17.2)$ & 0.04 \\
\hline Parent-PedsQL & Communication & $0-\mathrm{M}, n=8$ & $53.1(34.5)$ & $67.7(32.6)$ & $14.6(20.8)$ & 0.087 \\
\hline Parent-PedsQL & Communication & $\mathrm{M}-\mathrm{M}, n=11$ & $37.9(42.1)$ & $-3.8(15.5)$ & 0.437 & 0.056 \\
\hline Family Impact & Emotional Functioning & 0 or $\mathrm{L}, n=19$ & $60.0(16.2)$ & $64.7(15.6)$ & $4.7(9.9)$ & 0.052 \\
\hline Family Impact & Emotional Functioning & $0-\mathrm{M}, n=8$ & $56.2(7.5)$ & $65.4(15.3)$ & $7.5(2.9)$ & 0.014 \\
\hline Family Impact & Emotional Functioning & M-M, $n=11$ & $53.0(16.7)$ & $57.1(28.5)$ & $8.0(12.7)$ & 0.078 \\
\hline Family Impact & Communication & $0-\mathrm{M}, n=8$ & $54.2(10.8)$ & $55.6(26.7)$ & $8.3(6.8)$ & 0.092 \\
\hline Family Impact & Communication & $\mathrm{M}-\mathrm{M}, n=11$ & $43.3(19.6)$ & $54.2(25.0)$ & $13.3(17.7)$ & 0.041 \\
\hline Family Impact & Worry & M-M, $n=11$ & $44.5(16.1)$ & $57.9(23.2)$ & $10.5(15.2)$ & 0.056 \\
\hline Family Impact & HRQL Summary Score & $\mathrm{M}-\mathrm{M}, n=11$ & $47.0(12.2)$ & $52.7(26.6)$ & $7.2(11.6)$ & 0.08 \\
\hline Family Impact & Family Impact Total Score & $\mathrm{M}-\mathrm{M}, n=11$ & $45.7(13.0)$ & $52.4(26.1)$ & $8.6(10.2)$ & 0.027 \\
\hline
\end{tabular}

Abbreviations $-0=$ No Nusinersen, $\mathrm{L}=$ Loading Phase, and $\mathrm{M}=$ Maintenance Dosing.

Patients on the maintenance dosing at the time of the initial questionnaire and therefore on maintenance therapy for longer duration (increased time exposure to nusinersen) demonstrated significant improvements in communication $(43.3+/-19.6 \rightarrow 54.2+/-25$, $p=0.041$ ). Per the Parental-PedsQL, improvements in communication trended towards improvement in patients initiating therapy and reaching maintenance dosing (Cohort 2) $(53.1+/-34.5 \rightarrow 67.7+/-32.6, p=0.089)$ and became significant when pooled with Cohort 3 $(45.2+/-34.5 \rightarrow 53.9+/-33.7, p=0.04)$ demonstrating an improvement in communication scores when maintenance dosing was achieved and sustained.

Improvements in daily activities $(39.1+/-28.1 \rightarrow 52.6+/-32.5, p=0.065)$ and PedsQL Family Impact Total Score $(59.2+/-21.2 \rightarrow 64.2+/-21.8, p=0.081)$ domains trended towards significance in the population with SMA Type 2.

Patients on the maintenance dosing at the time of the initial questionnaire (again, with increased time exposure to nusinersen) demonstrated significant improvements in PedsQL Family Impact Total Score $(45.7+/-13 \rightarrow 52.6+/-26.1 ; p=0.027)$.

While the majority of findings demonstrated improvements for the patents and families undergoing nusinersen treatment, several unaccepted adverse findings became apparent. First, the Family Resources Domain in the Child-PedsQL $(\mathrm{N}=4)$ was significantly higher at follow up in the SMA Type 1 cohort $(36.7+/-15.3 \rightarrow 71.2+/-31.7, p=0.003)$ and appeared to most affect those progressing from the loading to the maintenance phase $(52.5+/-26 \rightarrow 71.7+/-15.4 ; p=0.015)(\mathrm{N}=7)$ and trended similarly in the Parental-PedsQL for patients with SMA Type $3(58.8+/-12.5 \rightarrow 68.8+/-15.5, p=0.066)$.

Increases in the Worry domain also trended towards significance in our Family Impact Module for the SMA Type 1 cohort $(45+/-12.7 \rightarrow 50.8+/-12.6 ; p=0.054)$ and surprisingly for those on the maintenance dosing for the entirety of this study (Cohort 4 ) $44.5+/-16.1 \rightarrow 57.9+/-23.2, p=0.056$.

\section{Discussion}

In the PedsQL scale, a change of 5 in the Standard Error of the Mean (SEM) has been pre-determined to represent a minimally clinically important difference $[17,18]$. Thus, 
while noted change did not reach statistical significant difference when the at-large group was analyzed, MCID was reached for communication and family resources according to child self-report.

The major domains impacted during nusinersen treatment between the no treatment cohort and all SMA types were communication and emotional functioning. The major domain impacted during nusinersen treatment between SMA Type 1 and other SMA types was worry. Of interest, improvements in daily activities and Family Impact total score were significant only in patients with SMA Type 2. This may be due to the number of patients with Type 2 included in this study or may be due to other factors since there was no difference observed in baseline and follow up. Prior analyses by SMA type have revealed benefits in axial, proximal, and distal motor function, particularly for those with more severe forms of the disorder [3,4].

In this cross-sectional clinical study, utilizing patient reported outcome measures validated in the SMA population, nusinersen therapy was found to improve communication and emotional functioning in subsets of the population. However, several unexpected potentially negative findings including increases in family resources and trends towards increases in worry (particularly in those on the medication for the longest period of time) warrant further consideration.

\subsection{Improvement in Communication and Emotional Functioning}

This study revealed the benefits of nusinersen on psychosocial function beyond physiologic metrics, recognizing the importance of family communication for starting the medication and in goal setting for sustaining the medication. Nusinersen has been shown to prolong survival in infants with SMA [19-22] and improve motor function [23,24] and yet the impact of treatment options on family-based communication quality and satisfaction has been under-explored. The PedsQL FIM specifically asks about the experience of the family in communicating with the child's doctors and nurses about how they feel in addition to questions about communicating with friends and other extended family members. In a qualitative study of 19 parents engaged in decision making for their children with SMA, the most important factor for parental decision making was "honest communication with physicians" [25]. For parents in Germany whose children received nusinersen via an expanded access program, "good communication and trusting relationships with medical and non-medical staff at the hospital helped caregivers cope with the uncertainties associated with the treatment" [26]. Fifty-one parents of Swedish children with SMA emphasized the desire for health care professionals to not only possess knowledge but to provide knowledge [27], seemingly as a means to foster family communication and concordance in family decision making.

A population-based study among 34 Danish parents of children with severe SMA revealed the prioritized importance parents place on provider communication that specifies what SMA entails, the treatment options, and prognosis [28]. Among 95 parents of children with severe SMA in Denmark and Sweden, bereaved parents were significantly more satisfied with care than non-bereaved parents ( $81 \%$ vs. $29 \%)$, with noted emphasis on communication as part of care coordination [29].

While medical outcomes matter, families also highly regard and uphold the process of communication as formative in their family experience. Introducing nusinersen as a treatment option necessarily results in engagement about current and anticipated research findings, potential benefits and harms, and experiences of other families. This treatment-dialogue has potential to improve knowledge and empower communication within families.

\subsection{Increase in Use of Family Resources}

This study revealed that use of family resources was perceived as significantly increased for children with Type 1 SMA receiving nusinersen according to child self-report. Parents in this study did not document parallel perception of increased use of family 
resources according. This speaks to the pediatric patient's awareness of the investment of family time and finances to nusinersen as a biomedical intervention. The ways in which children with complex care needs may internally compare their resource requirements as compared to healthy peers or siblings, and how this translates into a child's sense of self (whether the child views herself as worthy or as burdensome) or perception of stress (whether the child carries undue fear about fiscal wellness for others in the family) have been under-explored and even under-recognized by health systems. Parents in this study may have normalized resource utilization out of deep regard for their child's access to the intervention and inability to place a resource measure on the infinite value of their child's life.

Parents of children starting nusinersen describe striving for longer duration of life and improved quality of life [30] in the setting of invasive treatment and complex care with frequent hospital-based procedures. Parents of children with SMA starting nusinersen have reported worries about the high cost and maintaining adequate insurance coverage; potential side effects, risk factors, and adverse events; and treatment time [31]. The indirect care coverage costs and foregone parental employment add to the direct medical costs along with the hidden cost of mental health strain [32]. In a study of 64 parents of children with SMA, family finances were depicted as an under-recognized and yet realistic family concern [33]. In a study of parents of children w / SMA Types 2 and 3 in Australia, parents described: "significant financial and caregiving burdens, adjusted career choices and limitations on career progression and a complex landscape of access to funding, equipment, support and resources" [32].

From a health system perspective, the average annual cost of SMA1 "ranged from $\$ 75,047$ to $\$ 196,429$ per year" [34]. The "incremental cost-effectiveness ratio (ICER) of nusinersen compared to standard of care in SMA1 ranged from $\$ 210,095$ to $\$ 1,150,455$ per quality-adjusted life years (QALY) gained." [34] In a health resource comparison study, patients in the SMA Type I group $(n=349)$ and SMA Type 1 nusineran group $(n=45)$ "experienced an average of 59.4 and 56.6 days with medical visits per-patient-per-year (PPPY), respectively, including 14.1 and 4.6 inpatient days." [35] Regardless of pharmaceutical or hospital-use economic impact, families of children receiving motor, speech, and survival benefit from nusinersen speak of the miraculous impact of the medication, which exceeds a describable cost value for those children and families.

\subsection{Increase in Worry}

An important finding from this study was how worry started at the lowest in the maintenance cohort, but worry notably increased longitudinally. Prior studies have shown worry peak at time of decision making about starting a new medication with unknown outcomes and concern for side effects. While nusinersen has been shown to prolong survival in infants with SMA [19-22] and improve motor function [23,24], the parents involved in this study engaged in treatment decision making prior to the more recent accumulation of outcomes-based data and thus were venturing into the unknown.

Guilt regarding genetic diagnoses and uncertainties introduced by new therapies compound the underlying unpredictable trajectory of SMA [36,37], resulting in realistic worry at medication start. Parents of children starting nusinersen report worrying about "making difficult treatment choices" as well as "reactions, side effects, and worsening quality of life" $[33,38]$. A qualitative study of German parents of children with SMA Type 1 depicted "significant uncertainty and stress among caregivers prior to the actual treatment. Further, concerns persisted that nusinersen could not be approved or that the child could be excluded due to an insufficient treatment response" [26]. While medical teams may consider nusinersen generally well tolerated and efficacious, parents depict worry about their child not responding to nusinersen, requiring treatment interruptions, and experiencing complications [39].

As data show that earlier initiation of treatment is associated with more efficacy on functionality (such as ambulation) [40], family caregivers recognize time-sensitive decision 
making which may compound the sense of worry or urgency at initiation. Secondary spine and thorax deformities are frequent in children with SMA [41], adding worry for many families about not only the frequency of sedation but also the lumbar puncture itself [42]. Parents weigh the hoped-for benefits of nusinersen with concern about the child's discomfort. Even for parents of children with SMA who did not experience nusinersenrelated adverse events, realities of disease-specific adverse events such as cough, respiratory infections, and weakness continue to cause concern [4]. This study revealed that worry did not dissolve or mitigate with time, but instead seemed to increase longitudinally. This pattern of sustained worry as captured in this study hints at ongoing concern that patients and families have about whether the medication will continue working, whether there will be a delayed side effect, and the extent to which benefit may be sustained.

\subsection{Study Strengths and Limitations}

Strengths of this study include access to not only proxy-report but also pediatric patient-reported outcomes, now recognized as the gold standard for drug impact reporting [43]. Additional study strength includes use of quality of life metrics validated for this population and obtainment of surveys at more than one timepoint. Study limitations include single-site enrollment. This study did not control for whether children had missed any doses of nusinersen or adverse event/side effect profile of medication administration.

\section{Conclusions}

Nusinersen has offered a form of medical hope to children with SMA and their family caregivers with measurable impact on motor function and ambulation, despite the cost and challenges with administration. As the science advances to now include gene therapy, an interim goal would be additional treatment options with less burden on patients for SMA such as oral administration or one-time infusions. The lived experience of children with SMA receiving nusinersen warrants attentiveness towards ways to continually improve their quality of life. This includes consideration of ways to support family emotion and economic burden as well as foster family-centric communication. Future studies would ideally explore the impact of nusinersen and novel pharmaceutical interventions on functional abilities chronologically and longitudinally with correlated quality of life and family impact metrics.

Author Contributions: Conceptualization, A.Y., S.S. and M.A.H.; methodology, A.Y., S.S. and M.A.H.; software, S.H.; formal analysis, S.H.; investigation, M.S.W., A.Y., S.S., S.H. and M.A.H.; data curation, A.Y., S.S., S.H. and M.A.H. writing—original draft preparation, M.S.W. and M.A.H.; writing-review and editing, A.Y. and M.A.H.; supervision, M.A.H.; project administration, S.S. All authors have read and agreed to the published version of the manuscript.

Funding: The authors would like to acknowledge support from the UW-ICTR PCORI Pilot Program.

Institutional Review Board Statement: This study was conducted according to the guidelines of the Declaration of Helsinki, and approved by the local Institutional Review Board. The committee name is University of Wisconsin-Madison Minimal Risk IRB (Health Sciences). The ID for this study is 2015-1039. Initial Approval: 10 December 2015.

Informed Consent Statement: Informed consent and/or assent (age-dependent) was obtained from all subjects involved in this study.

Data Availability Statement: Data can be made available upon reasonable request to senior author.

Acknowledgments: Gratitude to the patients and families involved in this study. The authors would like to acknowledge support from the UW-ICTR PCORI Pilot Program.

Conflicts of Interest: The authors declare no conflict of interest. Weaver contributed to this paper in a private capacity. No official support or endorsement by the U.S. Department of Veterans Affairs is intended, nor should be inferred. 


\section{References}

1. Pechmann, A.; Kirschner, J. Diagnosis and New Treatment Avenues in Spinal Muscular Atrophy. Neuropediatrics 2017, 48, $273-281$. [CrossRef] [PubMed]

2. Ohmura, T.; Saeki, S.; Ogiwara, K.; Tobita, K.; Ling, Y.; Torii, S. Pharmacological and clinical profile of spinal muscular atrophy (SMA) therapeutic drug nusinersen (Spinraza(R)). Nihon Yakurigaku Zasshi 2018, 152, 147-159. [CrossRef]

3. Messina, S.; Sframeli, M.; Maggi, L.; D'Amico, A.; Bruno, C.; Comi, G.; Mercuri, E. Spinal muscular atrophy: State of the art and new therapeutic strategies. Neurol. Sci. 2021, 1-10. [CrossRef]

4. Acsadi, G.; Crawford, T.O.; Muller-Felber, W.; Shieh, P.B.; Richardson, R.; Natarajan, N.; Castro, D.; Ramirez-Schrempp, D.; Gambino, G.; Sun, P.; et al. Safety and efficacy of nusinersen in spinal muscular atrophy: The EMBRACE study. Muscle Nerve 2021, 63, 668-677. [CrossRef] [PubMed]

5. De Vivo, D.C.; Bertini, E.; Swoboda, K.J.; Hwu, W.-L.; Crawford, T.O.; Finkel, R.S.; Kirschner, J.; Kuntz, N.L.; Parsons, J.A.; Ryan, M.M.; et al. Nusinersen initiated in infants during the presymptomatic stage of spinal muscular atrophy: Interim efficacy and safety results from the Phase 2 NURTURE study. Neuromuscul Disord. 2019, 29, 842-856. [CrossRef] [PubMed]

6. Lovgren, M.; Sejersen, T.; Kreicbergs, U. Parents' Experiences and Wishes at End of Life in Children with Spinal Muscular Atrophy Types I and II. J. Pediatr. 2016, 175, 201-205. [CrossRef] [PubMed]

7. Lovgren, M.; Sejersen, T.; Kreicbergs, U. Information and treatment decisions in severe spinal muscular atrophy: A parental follow-up. Eur. J. Paediatr. Neurol. 2016, 20, 830-838. [CrossRef] [PubMed]

8. Khanna, D.; Tsevat, J. Health-related quality of life-an introduction. Am. J. Manag. Care 2007, 13 (Suppl. 9), S218-S223.

9. Weaver, M.S.; Hanna, R.; Hetzel, S.; Patterson, K.; Yuroff, A.; Sund, S.; Schultz, M.; Schroth, M.; Halanski, M.A. A Prospective, Crossover Survey Study of Child- and Proxy-Reported Quality of Life According to Spinal Muscular Atrophy Type and Medical Interventions. J. Child Neurol. 2020, 35, 322-330. [CrossRef]

10. Klug, C.; Schreiber-Katz, O.; Thiele, S.; Schorling, E.; Zowe, J.; Reilich, P.; Walter, M.C.; Nagels, K.H. Disease burden of spinal muscular atrophy in Germany. Orphanet J. Rare Dis. 2016, 11, 58. [CrossRef]

11. Iannaccone, S.T.; Hynan, L.S.; Morton, A.; Buchanan, R.; Limbers, C.A.; Varni, J.W.; AmSMART Group. The PedsQL in pediatric patients with Spinal Muscular Atrophy: Feasibility, reliability, and validity of the Pediatric Quality of Life Inventory Generic Core Scales and Neuromuscular Module. Neuromuscul Disord. 2009, 19, 805-812. [CrossRef] [PubMed]

12. Kocova, H.; Dvorackova, O.; Vondracek, P.; Haberlova, J. Health-related quality of life in children and adolescents with spinal muscular atrophy in the Czech Republic. Pediatric Neurol. 2014, 50, 591-594. [CrossRef]

13. Varni, J.W.; Sherman, S.A.; Burwinkle, T.M.; Dickinson, P.E.; Dixon, P. The PedsQL Family Impact Module: Preliminary reliability and validity. Health Qual. Life Outcomes 2004, 2, 55. [CrossRef]

14. Benjamini, Y.; Hochberg, Y. Controlling the False Discovery Rate: A Practical and Powerful Approach to Multiple Testing. J. R. Stat. Soc. Ser. B Methodol. 1995, 57, 289-300. [CrossRef]

15. Holm, S. A simple sequentially rejective multiple test procedure. Scand. J. Stat. 1979, 6, 65-70.

16. Team RC. A language and environment for statistical computing. Available online: https://www.R-project.org/ (accessed on 24 May 2019).

17. Norman, G.R.; Sloan, J.A.; Wyrwich, K.W. Interpretation of changes in health-related quality of life: The remarkable universality of half a standard deviation. Med. Care 2003, 41, 582-592. [CrossRef]

18. Weaver, M.; Wichman, C.; Darnall, C.; Bace, S.; Vail, C.; MacFadyen, A. Proxy-Reported Quality of Life and Family Impact for Children Followed Longitudinally by a Pediatric Palliative Care Team. J. Palliat. Med. 2018, 21, 241-244. [CrossRef] [PubMed]

19. Chiriboga, C.A.; Swoboda, K.J.; Darras, B.T.; Iannaccone, S.T.; Montes, J.; De Vivo, D.C.; Norris, D.A.; Bennett, C.F.; Bishop, K.M. Results from a phase 1 study of nusinersen (ISIS-SMN(Rx)) in children with spinal muscular atrophy. Neurology 2016, 86, 890-897. [CrossRef]

20. Finkel, R.S.; Chiriboga, C.A.; Vajsar, J.; Day, J.W.; Montes, J.; De Vivo, D.C.; Bishop, K.M.; Foster, R.; Liu, Y.; Ramirez-Schrempp, D.; et al. Treatment of infantile-onset spinal muscular atrophy with nusinersen: A phase 2, open-label, dose-escalation study. Lancet 2016, 388, 3017-3026. [CrossRef]

21. Finkel, R.S.; Mercuri, E.; Darras, B.T.; Connolly, A.M.; Kuntz, N.L.; Kirschner, J.; Chiriboga, C.A.; Saito, K.; Servais, L.; Tizzano, E.; et al. Nusinersen versus Sham Control in Infantile-Onset Spinal Muscular Atrophy. N. Engl. J. Med. 2017, 377, 1723-1732. [CrossRef]

22. Mercuri, E.; Darras, B.T.; Chiriboga, C.A.; Day, J.W.; Campbell, C.; Connolly, A.M.; Iannaccone, S.T.; Kirschner, J.; Kuntz, N.L.; Saito, K.; et al. Nusinersen versus Sham Control in Later-Onset Spinal Muscular Atrophy. N. Engl. J. Med. 2018, 378, 625-635. [CrossRef]

23. Pane, M.; Coratti, G.; Sansone, V.A.; Messina, S.; Catteruccia, M.; Bruno, C.; Sframeli, M.; Albamonte, E.; Pedemonte, M.; D’Amico, A.; et al. Italian EAP Working Group. Type I SMA new natural history: Long-term data in nusinersen-treated patients. Ann. Clin. Transl. Neurol. 2021, 8, 548-557. [CrossRef]

24. Osredkar, D.; Jilkova, M.; Butenko, T.; Loboda, T.; Golli, T.; Fuchsová, P.; Rohlenová, M.; Haberlova, J. Children and young adults with spinal muscular atrophy treated with nusinersen. Eur. J. Paediatr. Neurol. 2020, 30, 1-8. [CrossRef]

25. van Kruijsbergen, M.; Schroder, C.D.; Ketelaar, M.; van der Pol, W.; Cuppen, I.; van deer Geest, A.; Asselman, F.-L.; Fischer, M.J.; Vissert-Meily, J.M.A.; Kars, M.C. Parents' perspectives on nusinersen treatment for children with spinal muscular atrophy. Dev. Med. Child Neurol. 2021, 63, 816-823. [CrossRef] 
26. Kiefer, P.; Kirschner, J.; Pechmann, A.; Langer, T. Experiences of caregivers of children with spinal muscular atrophy participating in the expanded access program for nusinersen: A longitudinal qualitative study. Orphanet J. Rare Dis. 2020, 15, 194. [CrossRef]

27. Hjorth, E.; Kreicbergs, U.; Sejersen, T.; Lovgren, M. Parents' advice to healthcare professionals working with children who have spinal muscular atrophy. Eur. J. Paediatr. Neurol. 2018, 22, 128-134. [CrossRef] [PubMed]

28. Beernaert, K.; Lovgren, M.; Jeppesen, J.; Werlauff, U.; Rahbek, J.; Sejersen, T.; Kreicbergs, U. Parents' Experiences of Information and Decision Making in the Care of Their Child With Severe Spinal Muscular Atrophy: A Population Survey. J. Child Neurol. 2019, 34, 210-215. [CrossRef]

29. Hjorth, E.; Kreicbergs, U.; Sejersen, T.; Jeppesen, J.; Werlauffm, U.; Rahbek, J.; Lövgren, M. Bereaved Parents More Satisfied With the Care Given to Their Child With Severe Spinal Muscular Atrophy Than Nonbereaved. J. Child Neurol. 2019, 34, 104-112. [CrossRef]

30. Benini, F.; Salamon, E.; Divisic, A.; Maghini, I.; Agosto, C. Acknowledging Limits: Statistics and the Child's Quality of Life in Spinal Muscular Atrophy. J. Paediatr. Child Health 2020, 56, 995-996. [CrossRef] [PubMed]

31. Pacione, M.; Siskind, C.E.; Day, J.W.; Tabor, H.K. Perspectives on Spinraza (Nusinersen) Treatment Study: Views of Individuals and Parents of Children Diagnosed with Spinal Muscular Atrophy. J. Neuromuscul Dis. 2019, 6, 119-131. [CrossRef] [PubMed]

32. Farrar, M.A.; Carey, K.A.; Paguinto, S.G.; Chambers, G.; Kasparian, N.A. Financial, opportunity and psychosocial costs of spinal muscular atrophy: An exploratory qualitative analysis of Australian carer perspectives. BMJ Open 2018, 8, e020907. [CrossRef]

33. Qian, Y.; McGraw, S.; Henne, J.; Jarecki, J.; Hobby, K.; Yeh, W.S. Understanding the experiences and needs of individuals with Spinal Muscular Atrophy and their parents: A qualitative study. BMC Neurol. 2015, 15, 217. [CrossRef] [PubMed]

34. Dangouloff, T.; Botty, C.; Beaudart, C.; Servais, L.; Hiligsmann, M. Systematic literature review of the economic burden of spinal muscular atrophy and economic evaluations of treatments. Orphanet J. Rare Dis. 2021, 16, 47. [CrossRef] [PubMed]

35. Droege, M.; Sproule, D.; Arjunji, R.; Gauthier-Loiselle, M.; Cloutier, M.; Dabbous, O. Economic burden of spinal muscular atrophy in the United States: A contemporary assessment. J. Med. Econ. 2020, 23, 70-79. [CrossRef]

36. James, C.A.; Hadley, D.W.; Holtzman, N.A.; Winkelstein, J.A. How does the mode of inheritance of a genetic condition influence families? A study of guilt, blame, stigma, and understanding of inheritance and reproductive risks in families with $\mathrm{X}$-linked and autosomal recessive diseases. Genet. Med. 2006, 8, 234-242. [CrossRef]

37. Arribas-Ayllon, M.; Sarangi, S.; Clarke, A. Managing self-responsibility through other-oriented blame: Family accounts of genetic testing. Soc. Sci. Med. 2008, 66, 1521-1532. [CrossRef] [PubMed]

38. Cruz, R.; Belter, L.; Wasnock, M.; Nazarelli, A.; Jarecki, J. Evaluating Benefit-risk Decision-making in Spinal Muscular Atrophy: A First-ever Study to Assess Risk Tolerance in the SMA Patient Community. Clin. Ther. 2019, 41, 943-960. [CrossRef] [PubMed]

39. Agosto, C.; Salamon, E.; Divisic, A.; Benedetti, F.; Giacomelli, L.; Shah, A.; Perilongo, G.; Benini, F. Do we always need to treat patients with spinal muscular atrophy? A personal view and experience. Orphanet J. Rare Dis. 2021, 16, 78. [CrossRef]

40. Audic, F.; de la Banda, M.G.G.; Bernoux, D.; Ramirez-Garcia, P.; Durigneux, J.; Barnerias, C.; Isapof, A.; Cuisset, J.; Cances, C.; Richelme, C.; et al. Effects of nusinersen after one year of treatment in 123 children with SMA type 1 or 2: A French real-life observational study. Orphanet J. Rare Dis. 2020, 15, 148. [CrossRef]

41. Johannsen, J.; Weiss, D.; Schlenker, F.; Groth, M.; Denecke, J. Intrathecal Administration of Nusinersen in Pediatric SMA Patients with and without Spine Deformities: Experiences and Challenges over 3 Years in a Single Center. Neuropediatrics 2020, 52, 179-185. [CrossRef]

42. Goedeker, N.L.; Gibbons, J.L.; Varadhachary, A.S.; Connolly, A.M.; Zaidman, C.M. Laboratory Monitoring of Nusinersen Safety. Muscle Nerve 2021, 63, 902-905. [CrossRef] [PubMed]

43. Leahy, A.B.; Steineck, A. Patient-Reported Outcomes in Pediatric Oncology: The Patient Voice as a Gold Standard. JAMA Pediatrics 2020, 174, e202868. [CrossRef] [PubMed] 